\title{
HBV triggers APOBEC2 expression through miR-122 regulation and affects the proliferation of liver cancer cells
}

\author{
AIMEI LI $^{*}{ }^{*}$, JING WU $^{2 *}$, AIXIA ZHAI $^{1 *}$, JUN QIAN $^{1}$, XINYANG WANG $^{1}$, \\ MAJJID A. QARIA ${ }^{1}$, QINGMENG ZHANG ${ }^{1}$, YUJUN LI ${ }^{1}$, YONG FANG ${ }^{1}$, \\ WENPING KAO ${ }^{1}$, WUQI SONG ${ }^{1}$, ZHIYI ZHANG ${ }^{3}$ and FENGMIN ZHANG ${ }^{1}$
}

\author{
${ }^{1}$ Wu Lien-Teh Institute, Department of Microbiology, Harbin Medical University, Harbin, Heilongjiang 150081; \\ ${ }^{2}$ Hangzhou Key Laboratory of Inflammation and Immunoregulation, Department of Basic Medical Science, \\ School of Medicine, Hangzhou Normal University, Hangzhou, Zhejiang 310000; ${ }^{3}$ Department of Rheumatology, \\ The First Affiliated Hospital, Harbin Medical University, Harbin, Heilongjiang 150081, P.R. China
}

Received March 4, 2019; Accepted July 15, 2019

DOI: 10.3892/ijo.2019.4870

\begin{abstract}
Hepatitis B virus (HBV) infection is responsible for $50 \%$ of liver cancer cases globally; this disease is one of the leading causes of cancer-associated mortality. One reported mechanism underlying the development of liver cancer is the mutation of tumor suppressor genes induced by the overexpression of apolipoprotein B mRNA-editing enzyme catalytic subunit 2 (APOBEC2) in hepatocytes. In addition, it has been observed that HBV inhibited microRNA (miR)-122 expression in hepatocytes; however, the molecular mechanisms involved in liver cancer development remain unknown and further investigations are required. In the present study, the mechanistic roles of $\mathrm{HBV}$ infection in modulating the expression of miR-122 and APOBEC2, and the development of liver cancer, were investigated. Reverse transcription-quantitative PCR and western blot analyses revealed that APOBEC2 expression was markedly upregulated following HBV infection. Of note, the expression profile of APOBEC2 in the Huh7 and HepG2 liver cancer cell lines opposed that of miR-122; this miR is the most abundant miRNA in the liver and has been associated with hepatocarcinogenesis. Mechanistically, it was demonstrated via a dual-luciferase assay that miR-122 could specifically bind to the 3'-untranslated region (3'UTR) of APOBEC2
\end{abstract}

Correspondence to: Professor Fengmin Zhang, Wu Lien-Teh Institute, Department of Microbiology, Harbin Medical University, 194 Xuefu Road, Harbin, Heilongjiang 150081, P.R. China

E-mail: fengminzhang@ems.hrbmu.edu.cn

Professor Zhiyi Zhang, Department of Rheumatology, The First Affiliated Hospital, Harbin Medical University, 23 Youzheng Road, Harbin, Heilongjiang 150081, P.R. China

E-mail: zhangzhiyi2014@163.com

${ }^{*}$ Contributed equally

Key words: hepatitis B virus, liver cancer, apolipoprotein B mRNA-editing enzyme catalytic subunit 2, miR-122, regulation
mRNA, inhibiting its expression. Collectively, the findings of the present study may provide insight into the mechanistic role of HBV infection in modulating the expression of miR-122, which targets the 3'UTR of APOBEC2 mRNA, subsequently inducing liver carcinogenesis.

\section{Introduction}

Liver cancer accounts for $\sim 500,000$ deaths annually, and is ranked as the second leading cause of cancer-associated mortality globally (1). The development of liver cancer is not completely understood; hepatitis B virus (HBV) infection is considered to be the most common cause of this disease (2). Individuals chronically infected with $\mathrm{HBV}$ are at major risk for developing liver cancer, with the risk 10-25-fold greater compared with non-infected individuals $(3,4)$. The pathogenesis of this disease is complex and requires further investigation. HBV induces liver cancer via distinct mechanisms. For example, the HBV X protein ( $\mathrm{HBx}$ ) produced by $\mathrm{HBV}$ is one of the most important factors that induce the development of liver cancer; a variety of metabolic pathways in hepatocytes are involved, and lead to disorders of liver function. HBx is critical for viral replication, pathogenesis and oncogenesis $(5,6)$. It is the most frequently integrated viral gene in liver cancer, altering various signal transduction pathways in hepatocytes by interacting with Bcl-2 and $\mathrm{Bcl}-\mathrm{xl}$, and regulating cellular microRNAs (miRNAs/miRs), which in turn promotes cell metastasis and hepatocellular proliferation (7-9). The surface proteins of HBV, including HBV surface antigen (HBsAg), are also crucial factors in $\mathrm{HBV}$-associated hepatocellular carcinogenesis; they interact with enoyl coenzyme A hydratase 1, jumping translocation breakpoint protein and aldolase A (10-12), thereby affecting cell proliferation and apoptosis. Another mechanism underlying the development of $\mathrm{HBV}$-associated liver cancer is the integration of HBV DNA into the host genome, which not only disrupts the normal expression of endogenous genes and induces the mutagenesis of numerous cancer-associated genes, but also leads to chromosomal instability $(13,14)$. Of note, mutations in the HBV genome have been linked to liver 
cancer (15). An additional mechanism of HBV-associated liver cancer development is inflammation induced by HBV, which leads to persistent damage mediated by the immune response against HBV-infected cells (16). Subsequently, this will induce the proliferation of bipotential hepatobiliary progenitors and differentiated hepatocytes rather than stem cells present in bile canaliculi, resulting in epigenetic and genetic lesions (17). Furthermore, chronic inflammation, which induces injury and the regeneration of hepatocytes, significantly increases the risk of hepatocarcinogenesis (16). Liver injury is not caused by $\mathrm{HBV}$ infection alone; the host immune response has been proposed to serve a vital role in this process (16). The infiltration of immune cells, and release of inflammatory cytokines and chemokines does not clear the virus effectively, instead causing damage to the hepatocytes (18).

Members of the apolipoprotein B mRNA-editing enzyme catalytic subunit (APOBEC) family have been reported to serve pivotal roles in the mutagenesis of various human genes. The APOBEC family comprises 11 members, including APOBEC1, -2, -3A, -3B, -3C, -3DE, -3F, -3G, -3H and -4, and activation-induced cytidine deaminase (AID) $(19,20)$. These enzymes possess a distinct range of biological functions and substrate specificities. APOBEC1 is the first and the best characterized APOBEC member; it is primarily expressed in gastrointestinal tissues and encodes a truncated apolipoprotein B polypeptide $(21,22)$. The APOBEC 3 proteins, particularly members $3 \mathrm{G}$ and $3 \mathrm{~F}$, induce the hypermutation of viral DNA, which then act as host defense factors against viruses (23-25). APOBEC4 is mainly detectable in mammal testes, and may be involved in spermatogenesis in humans (19). AID is primarily expressed in B lymphocytes, where it deaminates chromosomal DNA and triggers antibody gene diversification $(26,27)$. Conversely, the function of APOBEC2 is not well characterized. APOBEC2 was reported to be specifically expressed in cardiac and skeletal muscles (28); however, certain studies have suggested that $A P O B E C 2$ transcripts are ubiquitous in human tissues, including the liver $(29,30)$. In addition, the aberrant expression of $A P O B E C 2$ may contribute to the development of human liver cancer (31). APOBEC2 has been associated with nucleotide alterations in the transcripts of its target genes, including eukaryotic translation initiation factor $4 \gamma 2$ and PTEN, thereby promoting the development of liver cancer (31). In addition, APOBEC 2 expression was reported to be affected by proinflammatory cytokines via the nuclear factor $(\mathrm{NF})-\kappa \mathrm{B}$ pathway, which suggests a possible role for APOBEC2 in hepatic inflammation (30). In addition, it has been reported that HBV can inhibit miR-122 expression in hepatocytes (32), In the present study, it was revealed that APOBEC2 expression in hepatocytes was significantly elevated by HBV. Additionally, miR-122 was revealed to target the 3'-untranslated region (3'UTR) of APOBEC2 mRNA and inhibit its expression. Furthermore, based on the aforementioned findings, it was hypothesized that HBV induced the expression of APOBEC2 via downregulation of cellular miR-122 to promote the development of liver cancer.

\section{Materials and methods}

Cell culture and treatment. Liver cancer cell lines Huh7 and HepG2 (obtained from Cell Bank of the Chinese Academy of
Sciences; cell lines were characterized by DNA-fingerprinting and isozyme detection) were cultured in Dulbecco's Modified Eagle's medium (DMEM; Biological Industries) supplemented with $10 \%$ fetal bovine serum (FBS; Biological Industries). Cells were cultured with $100 \mathrm{U} / \mathrm{ml}$ of penicillin/streptomycin and incubated under humidified conditions at $37^{\circ} \mathrm{C}$ with $5 \% \mathrm{CO}_{2}$.

miRNA target prediction. The potential target sequences of miR-122 in APOBEC2 mRNA were predicted using microRNA. org (microrna.org/microrna/home.do) and RNAhybrid 2.2 (bibiserv.techfak.unibielefeld.de/rnahybrid) based on complementary sequences and minimum free energy (mfe).

Nucleotides and plasmids. Sense and antisense miR-122 mimic (5'-TGGAGTGTGACAATGGTGTTTG-3' and 5'-CAAACA CCATTGTCACACTCCA-3'), 2'-O-methylated anti-miR-122 oligonucleotide (AMO-122; 5'-CAAACACCAUUGUCACAC UCCA-3') and respective control miRNAs [(miR-negative control (NC; 5'-UGGAGUGUGACAAUGGUGUUUG-3' and 5'-AACACCAUUGUCACACUCAAUU-3') and AMO-NC (5'-CAGUACUUUUGUGUAGUACAA-3')] were synthesized by Shanghai GenePharma Co., Ltd. The plasmid pGEMHBV, which contains a greater-than-unit-length cDNA of the HBV genome (payw1.2) (33) in a pGEM-72f(+) vector and expresses all HBV genes, was obtained from Harvard Medical School and is stored in our laboratory. For the pAPOBEC2 overexpression plasmid, which expresses APOBEC2 and enhanced green fluorescence protein (EGFP), APOBEC cDNA was inserted into the EcoRI and BamHI sites of the pEGFP-C1 vector (Clontech Laboratories, Inc.). For short hairpin RNA targeting APOBEC2 (shAPOBEC2), used to inhibit the expression of intracellular APOBEC2, shAPOBEC2 and shNC sequences were inserted into pGPU6 vectors (Shanghai GenePharma Co., Ltd.); the clone processes were supported by Genscript. Four shRNAs of APOBEC2 were constructed (shAPOBEC2-1, 2-2, 2-3 and 2-4), targeting different regions of the APOBEC2 sequence; shAPOBEC2-4 (5'-GGAGCAAGAAGAGGGTGA ATCTCAAGAGGATTCACCCTCTTCTTGCTCC-3') was seelcted for subsequent knockdown experiments after evaluation of interference efficiency, and was vector subsequently referred to as shAPOBEC2. shNC was used as control for shAPOBEC2 (5'-TTCTCCGAACGTGTCACGTCAAGAGAT TACGTGACACGTTCGGAGAA-3').

RNA and plasmid transfections. Huh7 and HepG2 cells, cultured in antibiotic-free DMEM with $10 \%$ FBS, were seeded in 6-, 24- or 96-well plates $\left(2 \times 10^{5}\right.$ cells $\left./ \mathrm{ml}\right)$ and incubated at $37^{\circ} \mathrm{C}$ with $5 \% \mathrm{CO}_{2}$ for $18-24 \mathrm{~h}$. All transfections were performed in Huh7 cells only, except for pGEMHBV, which was also transfected into HepG2 cells. Lipofectamine ${ }^{\circledR} 2000$ (Invitrogen; Thermo Fisher Scientific, Inc.) was used for transfection. The concentration of miRNA was 120 pmol (6-well), 40 pmol (24-well) or 10 pmol (96-well), whereas that of plasmids was $4 \mu \mathrm{g}$ (6-well), $1 \mu \mathrm{g}$ (24-well) or $0.25 \mu \mathrm{g}$ (96-well), respectively. pEGFP-C1, pAPOBEC2 and pGEMHBV contain EGFP as a transfection marker. Additionally, the expression of HBsAg of each group was detected using an ELISA kit (cat. no. YBS00192010; Kehua Biotech., Co., Ltd.) according to the manufacturer's protocols, and the absorbance was detected at $450 \mathrm{~nm}$. The cells were harvested at $24 \mathrm{~h}$ post-transfection for 
mRNA analysis, or at $48 \mathrm{~h}$ post-transfection for protein and cell viability analyses.

Reverse transcription-quantitative PCR (RT-qPCR) and gene expression analysis. According to the manufacturer's instructions, total RNA was extracted from treated cells using TRIzol ${ }^{\circledR}$ reagents (Thermo Fisher Scientific, Inc.) and $1 \mu \mathrm{g}$ RNA was reverse transcribed into cDNA using a PrimeScript ${ }^{\mathrm{TM}} \mathrm{RT}$ reagent kit with gDNA Eraser (cat. no. RR047A; Takara Bio, Inc.) at $42^{\circ} \mathrm{C}$ for $2 \mathrm{~min}, 37^{\circ} \mathrm{C}$ for $15 \mathrm{~min}$ and $85^{\circ} \mathrm{C}$ for $5 \mathrm{sec}$ prior to storage at $4^{\circ} \mathrm{C}$. qPCR was performed using SYBR PrimeScript Ex Taq II (Takara Bio, Inc.) in a LightCycler ${ }^{\circledR} 96$ System (Roche Diagnostics). qPCR was conducted as follows: $95^{\circ} \mathrm{C}$ for $5 \mathrm{~min}$, then 45 cycles of $95^{\circ} \mathrm{C}$ for $15 \mathrm{sec}, 60^{\circ} \mathrm{C}$ for $15 \mathrm{sec}$ and $72^{\circ} \mathrm{C}$ for $20 \mathrm{sec}$, with a final step at $72^{\circ} \mathrm{C}$ for $5 \mathrm{sec}$. Fold variations in expression between RNA samples were calculated after normalization with U6 RNA or GAPDH Mrna (34). The primer sequences used in the present study were as follows: APOBEC2, forward 5'-CCAGGCTGCTCTGAAGAAGC-3', reverse 5'-AGGCCTTGGATTCACCCTCT-3'; IL-6, forward 5'-CATTCTGCCCTCGAGCCCACC-3', reverse 5'-GGC AGCAGGCAACACCAGGA-3'; IKKe, forward 5'-TGC GTGCAGAAGTATCAAGC-3', reverse 5'-TACAGGCAG CCACAGAACAG-3'; TNF- $\alpha$, forward 5'-AGCCTGTAG CCCATGTTGTAG-3', reverse 5'-CTCTCAGCTCCACGC CATTG-3'. GAPDH, forward 5'-ATCACTGCCACCCAG AAGAC-3', reverse 5'-TTTCTAGACGGCAGGTCAGG-3'; U6, forward 5'-GCTTCGGCAGCACATATACTAAAA T-3', reverse 5'-CGCTTCACGAATTTGCGTGTCAT-3'; miR-122, forward 5'-GGGTGGAGTGTGACAATGG-3', reverse 5'-TGCGTGTCGTGGAGTC-3'.

Western blotting. Protein was extracted using radioimmunoprecipitation assay buffer (Pierce; Thermo Fisher Scientific, Inc.) with PMSF cocktail. An enhanced Bicinchoninic Acid Protein Assay kit (cat. no. P0010S; Beyotime Institute of Biotechnology) was used to determine the protein concentration, and $35 \mu \mathrm{g} /$ lane protein was resolved via $12 \%$ SDS-PAGE, followed by electrotransfer onto nitrocellulose membranes. Polyclonal APOBEC2 (1:500; cat. no. 20121-1-AP; ProteinTech Group, Inc.) and cleaved-caspase-3 antibodies (1:500; cat. no. WL01857; Wanleibio Co., Ltd.), and monoclonal antibodies against $\beta$-actin (cat. no. TA-09; Beijing Zhongshan Golden Bridge Biotechnology Co., Ltd.; OriGene Technologies, Inc.) were used for immunoblotting overnight at $4^{\circ} \mathrm{C}$. After a standard washing with TBS-Tween 20 (Sigma-Aldrich; Merck $\mathrm{KGaA}$ ), membranes were incubated with horseradish peroxidase-conjugated goat anti-mouse and anti-rabbit (1:2,500; cat. nos. ZB-2305 and ZB-2301, respectively; Beijing Zhongshan Golden Bridge Biotechnology Co., Ltd.; OriGene Technologies, Inc.) for $2 \mathrm{~h}$ at room temperature. The signal was visualized using an enhanced chemiluminescence western blot substrate (Thermo Fisher Scientific Inc.); bands were imaged with a charge-coupled camera LAS4000 (Fujifilm) and quantified with Image J (v1.51k; National Institutes of Health).

Dual-luciferase assay. PCR was used to amplify the 3'UTR sequence of $A P O B E C 2$, and the amplification primers were as follows: Forward 5'-GCGCTCGAGGCAACTGGGCTTTGC
CTC-3' (XhoI restriction site underlined), reverse 5'-AATGCG GCCGCCTGCCATTACCATCAAACAC-3' (NotI restriction site underlined). The PCR products were purified and cloned downstream of the Renilla luciferase gene of the dual-luciferase vector, pmiR-RB-REPORT ${ }^{\mathrm{TM}}$ [APOBEC2-wild type (WT); Guangzhou RiboBio Co., Ltd.]. To investigate the potential interaction between miR-122 and APOBEC2, site-directed mutagenesis was performed to mutate the miR-122 target sites in the APOBEC2 3'UTR region, replacing ACACTCC with TGTGAGG; thus, the mutant (MUT) APOBEC2 luciferase reporter vector was constructed (APOBEC2-MUT). For the luciferase reporter assay, Huh7 cells $\left(4 \times 10^{4}\right.$ cells) were seeded in 96-well plates for $24 \mathrm{~h}$. Luciferase reporter vectors $(0.25 \mu \mathrm{g})$ were co-transfected with miR-122 mimic or miR-NC (10 pmol) into cells using Lipofectamine 2000. After $48 \mathrm{~h}$ of incubation, the treated cells were harvested and analyzed using a Dual-Luciferase Assay kit (Promega Corporation). The data were presented as the relative luciferase activity (Renilla luciferase/firefly luciferase). Luminescence was quantified using a luminometer (Turner BioSystems). All experiments were performed in triplicate.

MTT assay. Huh7 cells were seeded in 96-well plates and incubated overnight; pAPOBEC2, shAPOBEC2 or corresponding control vectors were then transfected into cells using Lipofectamine 2000. At $48 \mathrm{~h}$ following treatment, sterile MTT was added to the culture supernatant at $20 \mathrm{il} /$ well $(5 \mathrm{mg} / \mathrm{ml})$. After incubation at $37^{\circ} \mathrm{C}$ with $5 \% \mathrm{CO}_{2}$ for $4 \mathrm{~h}, 100$ ìl dimethyl sulfoxide was added to the supernatant and vortexed for $10 \mathrm{~min}$ to dissolve the formazan crystals. The absorbance was measured at $490 \mathrm{~nm}$ using a microplate reader.

Statistical analysis. All results were presented as the mean \pm standard error of the mean. A two-tailed Student's t-test was used to evaluate the differences between two groups. For multiple comparisons one-way ANOVA followed by Tukey's or Dunnett's test was performed. $\mathrm{P}<0.05$ was considered a statistically significant difference. Statistical analysis was performed using SigmaPlot 11.0 (Systat Software, Inc.) and GraphPad Prism 5 (GraphPad Software, Inc.). All experiments were repeated at least three times independently.

\section{Results}

HBV transfection induces APOBEC2 expression in liver cells. It was previously reported that aberrant APOBEC2 expression was involved in the development of liver cancer (31). To investigate the role of $\mathrm{HBV}$ infection in modulating APOBEC2 expression and the subsequent induction of carcinogenesis, Huh7 and HepG2 cells were transfected with plasmids expressing HBV proteins (pGEMHBV) or the control (pEGFP-C1). The expression of HBsAg in the pGEMHBV group increased significantly compared with the control group (Fig. S1). RT-qPCR analysis revealed that the relative mRNA expression levels of APOBEC2 were significantly increased in pGEMHBV-transfected cells compared with pEGFP-C1-transfected cells in both cell lines (Fig. 1A and C). Similarly, the protein expression levels of APOBEC2 were upregulated in cells transfected with pGEMHBV compared with those transfected with pEGFP-C1 (Fig. 1B and D). Therefore, HBV was 

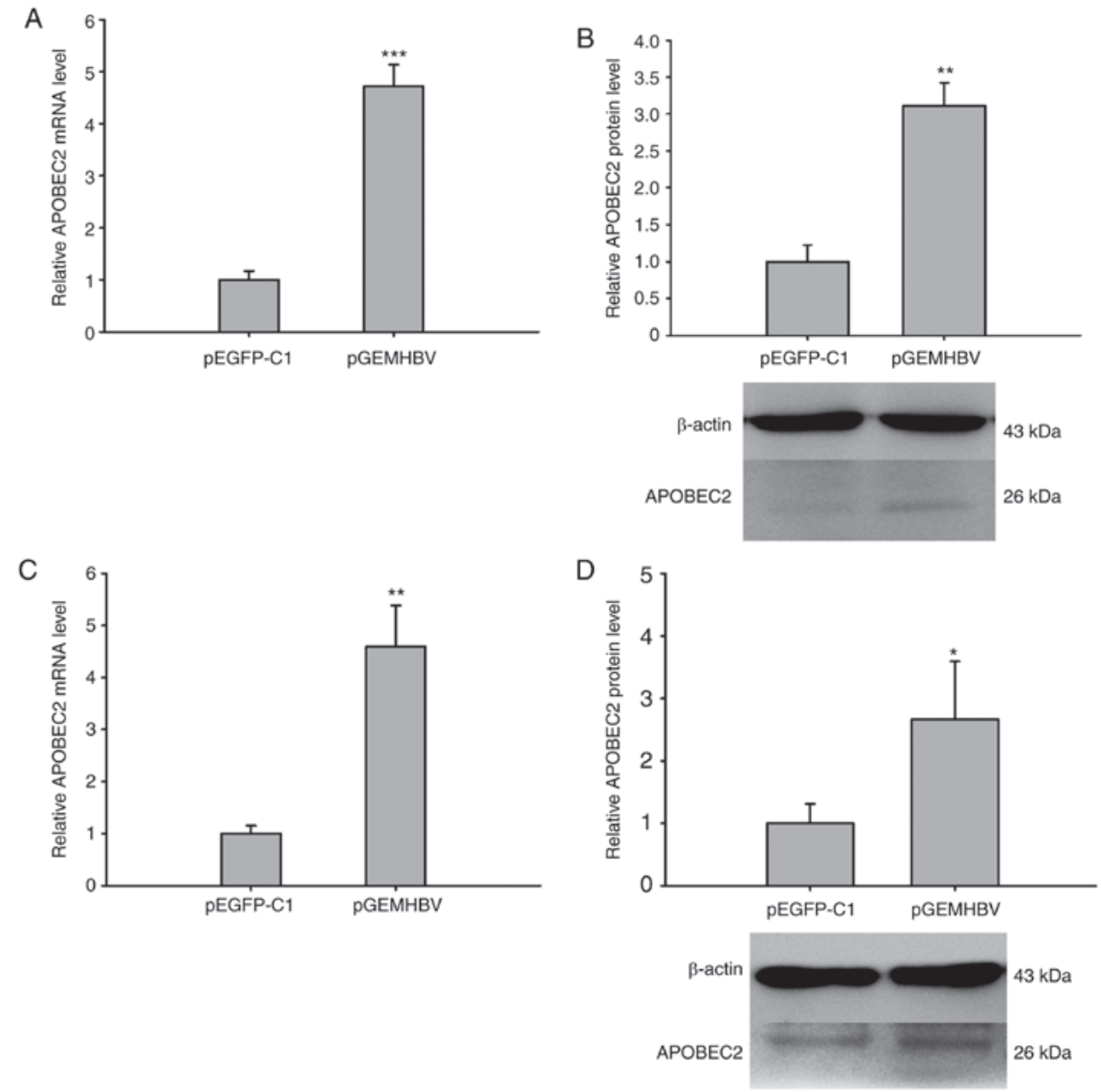

Figure 1. APOBEC2 expression in liver cancer cells following HBV infection. Huh7 and HepG2 cells at 70\% confluence were transfected with pGEMHBV or pEGFP-C1 for $24 \mathrm{~h}$ (mRNA analysis) or $48 \mathrm{~h}$ (protein analysis). Expression of APOBEC2 (A) mRNA and (B) protein expression in Huh7 cells. Expression of APOBEC2 (C) mRNA and (D) protein expression in HepG2 cells. pEGFP-C1 was used as a negative control for pGEMHBV. $\beta$-actin served as an internal control. Data are presented as the mean \pm standard error of the mean $(n=3) .{ }^{*} \mathrm{P}<0.05,{ }^{* * *} \mathrm{P}<0.01,{ }^{* * * *} \mathrm{P}<0.001$ vs. pEGFP-C1. APOBEC2, apolipoprotein $\mathrm{B}$ mRNA-editing enzyme catalytic subunit 2; EGFP, enhanced green fluorescent protein; HBV, hepatitis B virus.

proposed to promote APOBEC2 expression at the mRNA and protein levels in liver cancer cells.

Modulation of APOBEC2 expression affects cell viability and apoptosis. To study the role of APOBEC2 in cell proliferation, APOBEC2 overexpression (pAPOBEC2) and APOBEC2 interference plasmid (shAPOBEC2) vectors were constructed, which were respectively transfected into Huh7 cells to regulate cellular APOBEC2 expression. As presented in Fig. 2, four shAPOBEC2 vectors were constructed; shAPOBEC2-4 exhibited the highest interference efficiency at the mRNA and protein levels. Therefore, shAPOBEC2-4 was used in subsequent experiments. RT-qPCR and western blot analyses revealed that transfection with pAPOBEC2 significantly upregulated the expression of APOBEC2 in Huh7 cells (Fig. S2). An MTT assay revealed that pAPOBEC2-transfected cells exhibited significantly increased viability compared with those transfected with pEGFP-C1 (Fig. 3A). Conversely, shAPOBEC2-transfected cells exhibited significantly reduced viability compared with those transfected with shNC (Fig. 3B). In addition, as determined via western blotting, the expression of cleaved-caspase-3 (a terminal shear enzyme in apoptosis) was reduced following overexpression of APOBEC2, but was enhanced in response to APOBEC2 knockdown (Fig. 3C and D). In conclusion, APOBEC2 overexpression increased cell viability and decreased apoptosis, whereas APOBEC2 downregulation induced opposing effects in Huh7 cells.

miR-122 expression opposes APOBEC2 expression. To further explore the association between APOBEC 2 and liver cancer, the expression of APOBEC2 was analyzed in different liver cancer cell lines (HepG2 and the hepatoma cell Huh7). RT-qPCR analysis and western blotting revealed that the expression of APOBEC2 was upregulated in HepG2 cells compared with in Huh7 cells (Fig. 4A and B). Of note, the expression of miR-122 exhibited opposing expression trends to that of APOBEC2 in the two cell lines (Fig. 4C). Collectively, the results suggested that the expression of miR-122 was negatively associated with that of APOBEC2 in liver cells.

APOBEC2 is a target of miR-122 in liver cells. To analyze the association between miR-122 and APOBEC2, miR-122 was overexpressed via transfection with miR-122 mimic or knocked down via transfection with AMO-122 in Huh7 cells. The expression levels of miR-122 in miR-122 mimic-treated 
A

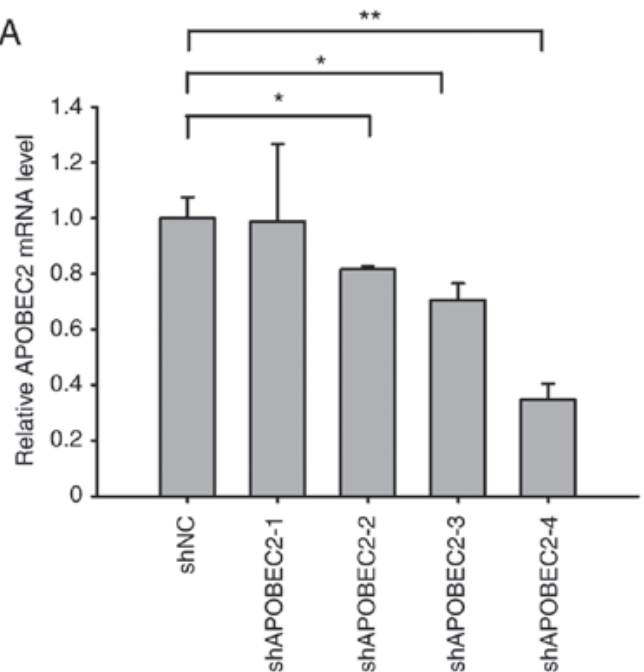

B

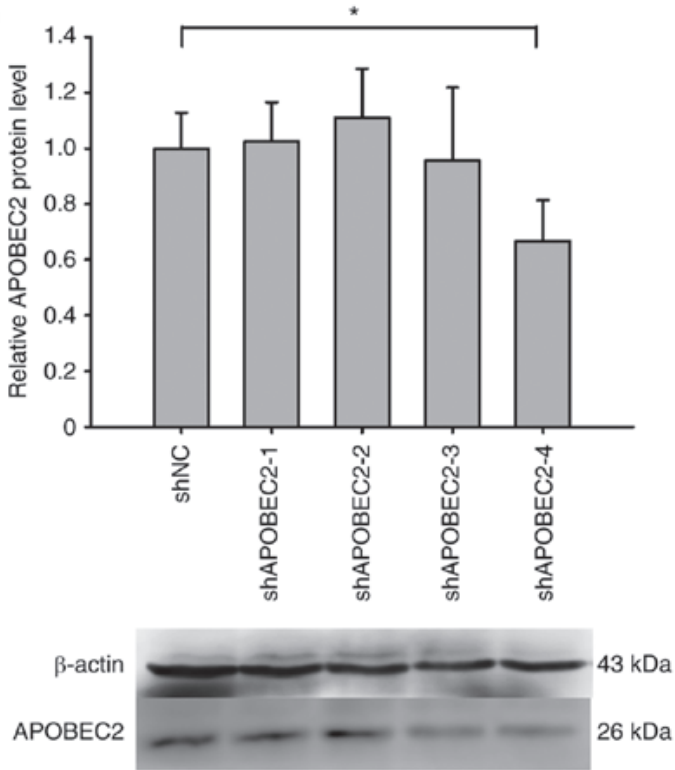

Figure 2. Verification of the inhibition efficiency of shRNAs on APOBEC2 expression. Four shRNAs specific for APOBEC2 were designed and transfected into Huh7 cells, and total RNA and protein were extracted at 24 and $48 \mathrm{~h}$ post-transfection, respectively. Then, reverse transcription-quantitative PCR and western blot analyses were conducted to detect the inhibition efficiency. Compared with shNC, shAPOBEC2-4 effectively inhibited APOBEC2 (A) mRNA and (B) protein expression; APOBEC2 mRNA and protein expression decreased by $\sim 70$ and $\sim 34 \%$, respectively, following APOBEC2 knockdown. Therefore, shAPOBEC2-4 was selected for further experimentation in the present study. shNC served as a control. Data are presented as the mean \pm standard error of the mean ( $\mathrm{n}=3) .{ }^{*} \mathrm{P}<0.05,{ }^{* *} \mathrm{P}<0.01$. APOBEC2, apolipoprotein B mRNA-editing enzyme catalytic subunit 2; NC, negative control; shRNAs, short hairpin RNA.

cells were significantly increased compared with miR-NC treated cells, whereas in AMO-122 treated cells, the expression levels of miR-122 were significantly suppressed (Fig. 5A and B). RT-qPCR and western blotting demonstrated that miR-122 overexpression resulted in a significant suppression of APOBEC2 expression. Conversely, miR-122 knockdown resulted in an increase in APOBEC2 expression (Fig. 5A-D), which further indicated that there may potential interaction between miR-122 and APOBEC2 mRNA.

To explore this hypothesis, microRNA.org and RNAhybrid 2.2, web-based RNA analysis tools, were employed to predict the potential target sites of miR-122 within APOBEC2 mRNA. It was revealed that there was a putative miR-122 target sequence in the 3'UTR of APOBEC2 mRNA. The target sequences perfectly matched the seed sequence of miR-122, and the mfe was $-26.0 \mathrm{kcal} / \mathrm{mol}$ (Fig. 5E). To further determine the potential interaction between miR-122 and $A P O B E C 2$ mRNA, the WT and MUT 3'UTR of APOBEC2 mRNA were inserted into pmiR-RB-REPORT vectors, generating APOBEC2-WT and APOBEC2-MUT vectors (Fig. 5F). As presented in Fig. 5G, the fluorescence of miR-122 and APOBEC2-WT co-transfection group was $~ 35 \%$ lower than that of the miR-NC and APOBEC2-WT co-transfection group; however, in the group co-transfected with APOBEC2-MUT, the decrease in fluorescence was eliminated. Collectively, the results of the present study indicated that miR-122 targeted the 3 'UTR of $A P O B E C 2$ mRNA and downregulated its expression.

$H B V$ infection suppresses miR-122 expression. Furthermore, to confirm whether $\mathrm{HBV}$ regulates APOBEC2 expression by directly suppressing that of miR-122, miR-122, AMO-122, and their corresponding controls were introduced separately into Huh7 cells. In addition, pGEMHBV was co-transfected with the aforementioned miRNAs. The expression levels of miR-122 and APOBEC2 were subsequently measured. The results demonstrated that pGEMHBV co-transfection significantly suppressed cellular miR-122 expression in the control groups (miR-NC and AMO-NC) compared with the pEGFP-C1 group (Fig. 6A), which was consistent with previous findings (32). In addition, miR-122 was significantly suppressed following co-transfection of pGEMHBV + AMO-122 compared with all other groups, whereas in the pGEMHBV + miR-122 co-transfection group, the expression of miR-122 didn't change significantly compared with the empty vector control (Fig. 6A). Conversely, the expression levels of APOBEC2 were increased in the pGEMHBV + miR-NC or pGEMHBV + AMO-NC co-transfection groups, and further increased following co-transfection with AMO-122, whereas APOBEC2 was downregulated in the pGEMHBV + miR-122 co-transfection group (Fig. 6B). Overall, transfection of HBV genes suppressed the expression of miR-122, which subsequently induced the expression of APOBEC2. These findings further suggested that the effects of HBV on APOBEC2 occur via the downregulation of cellular miR-122 expression, which may contribute to the tumorigenesis of liver cells (Fig. 7).

$H B V$ infection and APOBEC2 induce chronic inflammatory responses. Based on the fact that chronic inflammation is closely associated with tumor development (35), in the present study, the levels of IL- 6 , IKK $\varepsilon$ and TNF- $\alpha$, three notable proteins involved in both inflammatory and tumor-associated processes (36-39), were measured in Huh7 cells following 

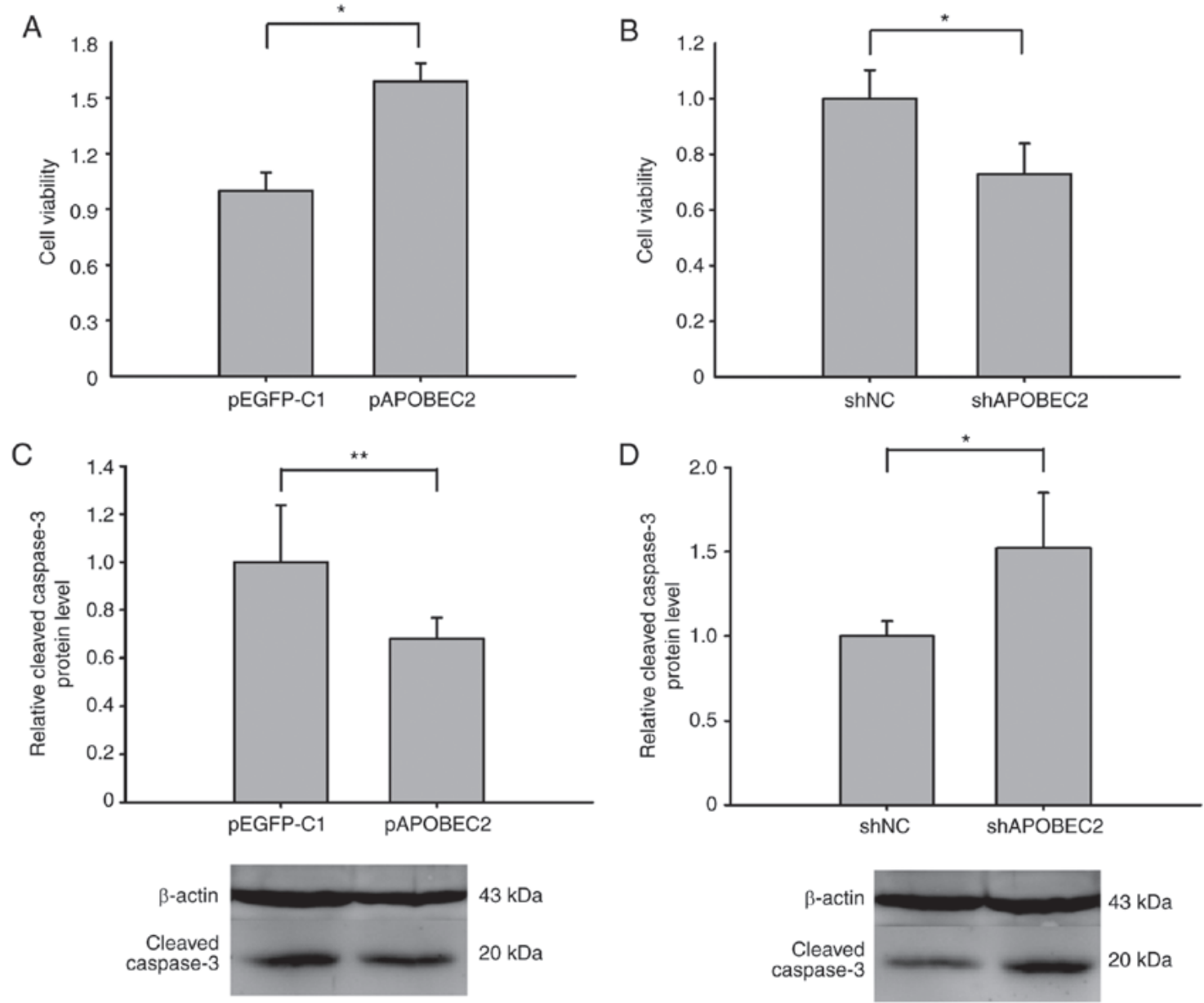

Figure 3. Modulation of APOBEC2 expression affects liver cancer cell viability and apoptosis. Huh7 cells at 70\% confluence were transfected with pAPOBEC2 or shAPOBEC2 for $48 \mathrm{~h}$ to increase or decrease cellular APOBEC2 expression, respectively. The effects of APOBEC 2 on cells were determined via MTT assay and western blotting. (A) APOBEC2 overexpression enhanced Huh7 cell viability compared with pEGFP-C1. (B) APOBEC2 suppression reduced Huh7 cell viability compared with shNC. (C) APOBEC2 overexpression increased cleaved-caspase-3 expression compared with pEGFP-C1. (D) APOBEC2 suppression reduced cleaved-caspase-3 expression compared with shNC. pEGFP-C1 and shNC were used as NCs for pAPOBEC2 and shAPOBEC2, respectively. $\beta$-actin served as an internal control. Data are presented as the mean \pm standard error of the mean $(n=3) .{ }^{*} \mathrm{P}<0.05,{ }^{* *} \mathrm{P}<0.01$. APOBEC2, apolipoprotein $\mathrm{B}$ mRNA-editing enzyme catalytic subunit 2; EGFP, enhanced green fluorescent protein; NC, negative control; shRNAs, short hairpin RNA.

transfection with pGEMHBV or pAPOBEC2. As presented in Fig. 8, the expression of IL-6 was 2.6-fold higher, and the expression levels of IKK $\varepsilon$ and TNF- $\alpha$ were 60 and $50 \%$ lower, respectively, compared with the control group following HBV infection. APOBEC2 overexpression induced similar effects on the levels of these three factors, with increased expression of IL-6, and downregulation of IKKe and TNF- $\alpha$.

\section{Discussion}

In the present study, the expression of APOBEC 2 was determined to be negatively associated with the liver-specific miRNA, miR-122, in different liver cell lines. Furthermore, it was demonstrated that miR-122 could specifically target the 3'UTR of $A P O B E C 2$ mRNA and inhibit its expression. It has been reported that HBV can inhibit miR-122 expression in hepatocytes (40), which was consistent with the present findings. In addition, this study demonstrated that the transfection of HBV genes significantly induced APOBEC 2 expression via miR-122 inhibition. Thus, the results suggested that HBV upregulates APOBEC2 expression and may promote cell proliferation.
APOBEC2 is a member of the cytidine deaminase family, APOBEC, with putative nucleotide editing activity (41). A total of 11 members comprise this family, including APOBEC1, -2, $-3 \mathrm{~A},-3 \mathrm{~B},-3 \mathrm{C},-3 \mathrm{DE},-3 \mathrm{~F},-3 \mathrm{G},-3 \mathrm{H}$ and -4 , and AID in humans, which participate in various physiological and pathological processes, such as lipid metabolism, viral infection, spermatogenesis and immune gene diversity $(19,20,42)$. At present, increasing evidence has indicated that the dysregulated expression and abnormal activity of APOBEC members may be associated with tumorigenesis via the nucleotide editing of tumor-related genes. It has been reported that overexpression of APOBEC1 induces dysplasia and the development of hepatocellular carcinoma in transgenic mouse livers (43), whereas constitutive expression of AID leads to frequent mutations of the T-cell receptor gene, Tp53 and c-myc gene, leading to the formation of malignant tumors in the liver, lung, stomach and lymphatic system $(44,45)$. APOBEC2 was primarily reported as being exclusively expressed in skeletal and cardiac muscle (28); however, accumulating evidence has indicated that $A P O B E C 2$ transcripts are ubiquitous in various tissues in humans, including the liver (29). Furthermore, overexpression of APOBEC2 in transgenic mice contributes to liver 

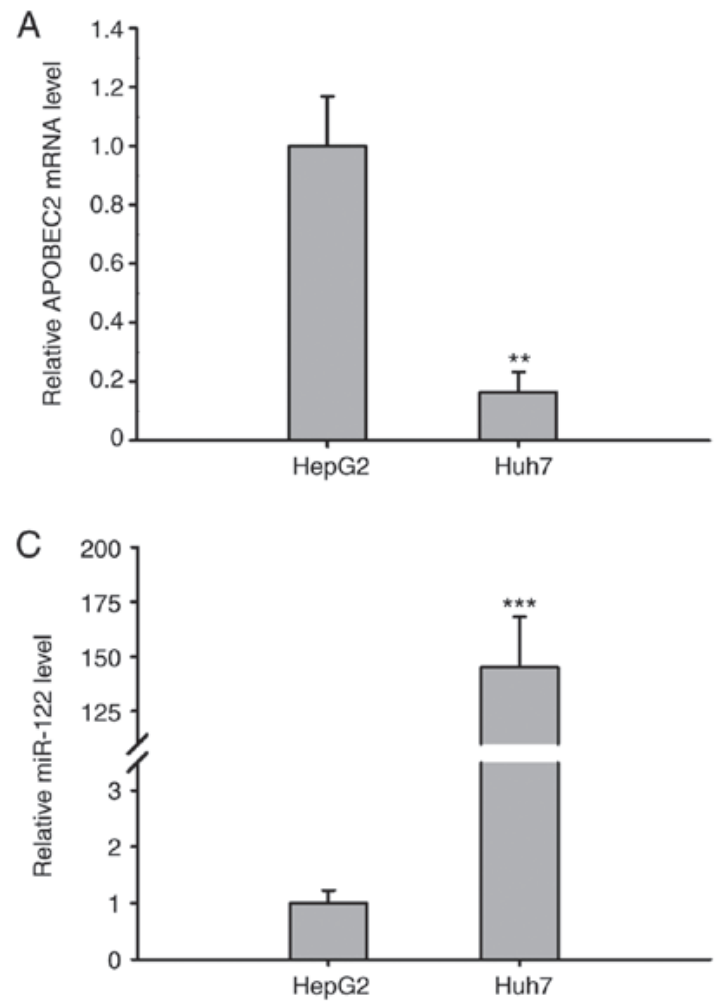
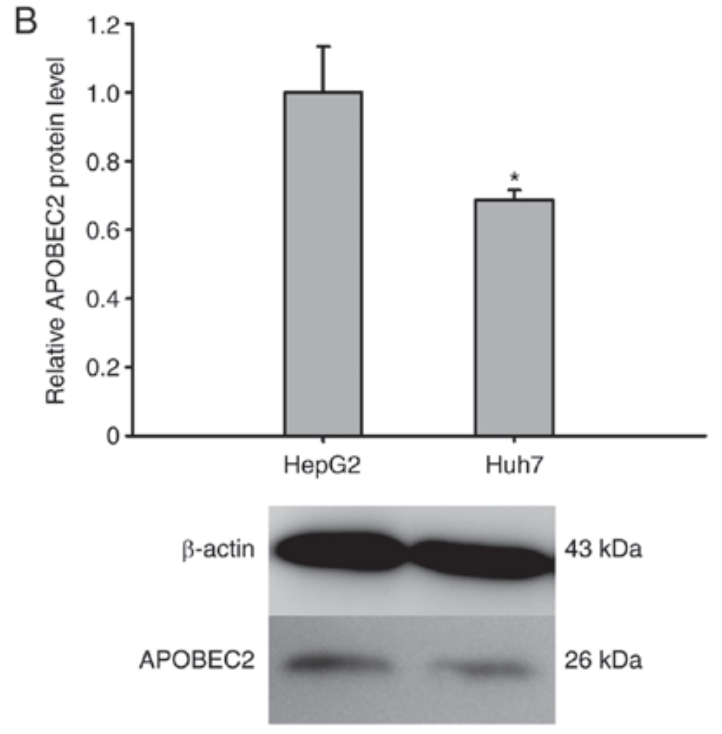

Figure 4. Expression of APOBEC2 and miR-122 in different liver cell lines. Total RNA and protein were extracted from Huh7 and HepG2 cells, and respectively subjected to reverse transcription-quantitative PCR and western blot analyses to evaluate miR-122 and APOBEC2 expression in these cells. (A and B) APOBEC2 mRNA and protein expression. (C) miR-122 expression. $\beta$-actin served as an internal control. Data are presented as the mean \pm standard error of the mean $(\mathrm{n}=3)$. ${ }^{*} \mathrm{P}<0.05,{ }^{* *} \mathrm{P}<0.01,{ }^{* * * *} \mathrm{P}<0.001$ vs. HepG2. APOBEC2, apolipoprotein B mRNA-editing enzyme catalytic subunit 2; miR-122, microRNA.

tumorigenesis (31); consistent with this, it was determined in the present study that overexpression of APOBEC2 significantly promoted cell viability. Additionally, the expression of cleaved-caspase-3 (a terminal shear enzyme in apoptosis) was reduced following APOBEC2 overexpression, indicating the suppression of cell apoptosis, whereas knockdown of APOBEC2 induced opposing effects. These findings indicated that APOBEC2 may increase the activity of liver cancer cells, suppress apoptosis, and promote the proliferation and survival of liver cells to contribute to HBV-induced liver cancer.

As a liver-specific miRNA, miR-122 constitutes $70 \%$ of the total population of miRNAs in hepatocytes, which is extensively involved in the physiological and pathological processes of liver cells $(46,47)$. It has been reported that miR-122 can target a variety of genes to inhibit liver cell growth and metastasis, such as cyclin G1, serum response factor, insulin-like growth factor 1 receptor, N-myc downstream-regulated gene 3, Bcl-w, Glucose-6-phosphate-dehydrogenase, a disintegrin and metalloprotease family (ADAM)10 and ADAM17 (48-53). The serum levels of alanine transaminase and aspartate transaminase were correlated with miR-122 expression, which suggested that the severity of chronic hepatitis B is positively associated with the expression of miR-122 (54). Conversely, miR-122 expression was significantly decreased in human liver cancer, and was associated with the prognosis of patients (53). In the present study, the expression of APOBEC2 was upregulated in HepG2 cells compared with in Huh7 cells. Of note, the expression profile of miR-122 in these cell lines opposed that of APOBEC2, which suggested a regulatory mechanism underlying APOBEC2 expression mediated by miR-122. Furthermore, it was reported that overexpression of miR-122 significantly suppressed APOBEC2 expression, whereas miR-122 knockdown resulted in opposing effects. These results indicated a potential interaction between miR-122 and $A P O B E C 2$ mRNA. After predicting potential target sites of miR-122 within the APOBEC2 mRNA, it was hypothesized that miR-122 could bind to the 3'UTR of APOBEC2 mRNA and inhibit its expression.

The mechanism underlying HBV-induced carcinogenesis is complex. In the present study, it was investigated as to whether the induction of APOBEC2 following HBV infection occurs via the suppression of cellular miR-122 to facilitate the growth of liver cancer cells. Thus, pGEMHBV was transfected into Huh7 cells; the results revealed that the expression of miR-122 was decreased, whereas that of APOBEC2 was increased. Furthermore, Huh7 cells were co-transfected with pGEMHBV + miR-122 mimic or inhibitor. APOBEC2 exhibited the highest degree of upregulation in pGEMHBV and AMO-122 co-transfected cells; however, this was not observed in the pGEMHBV and miR-122 co-transfection group. Thus, the present findings may indicate a novel mechanism underlying the development of HBV-induced liver cancer.

As chronic hepatitis has been associated with the occurrence of liver cancer, the expression of several inflammatory factors was also detected, including interleukin-6 (IL-6), IкB kinase $\varepsilon(\mathrm{IKK} \varepsilon)$, and tumor necrosis factor- $\alpha$ (TNF- $\alpha)$ after transfecting cells with HBV genes or APOBEC2. The results revealed that the expression of IL- 6 was increased, whereas that 

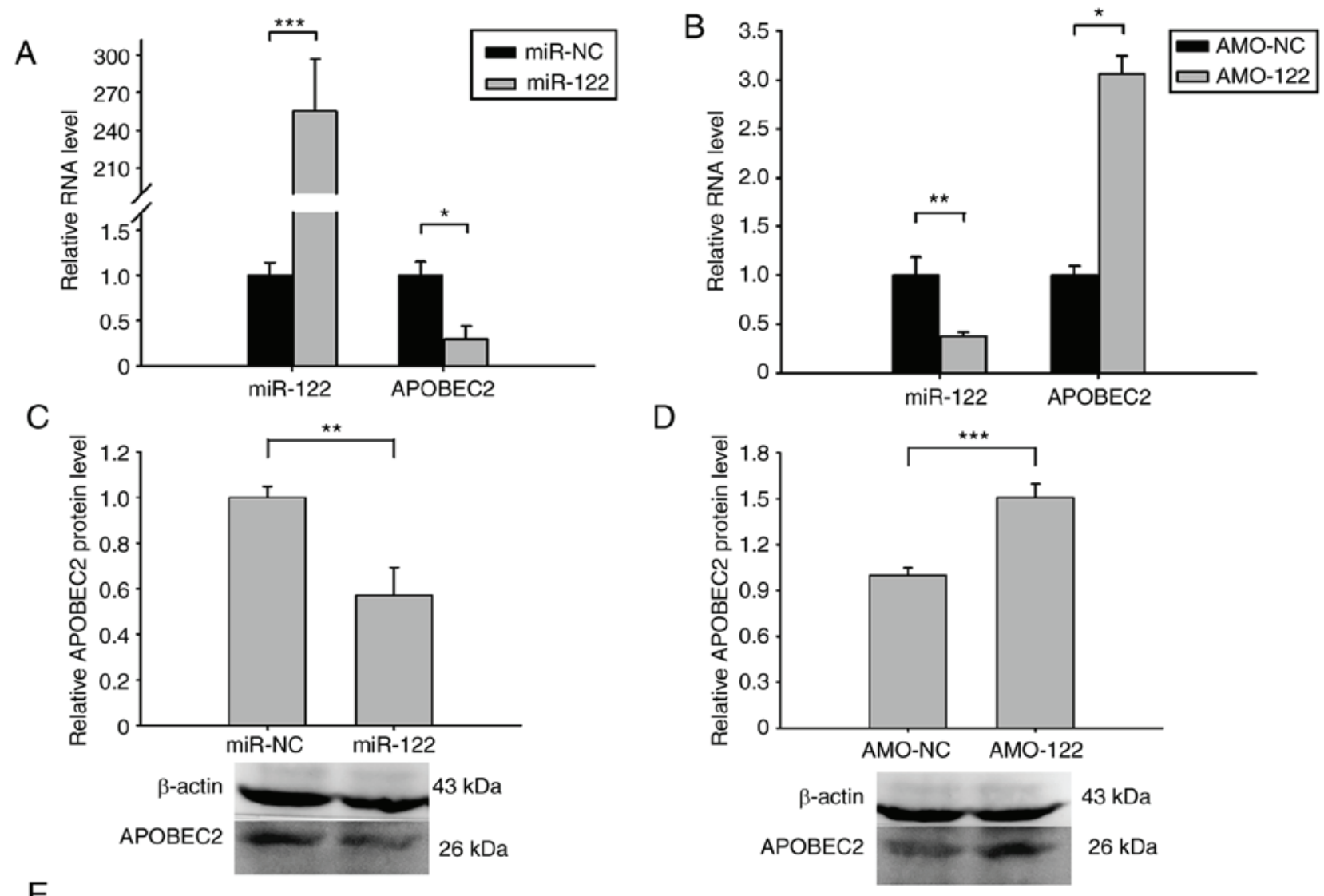

E
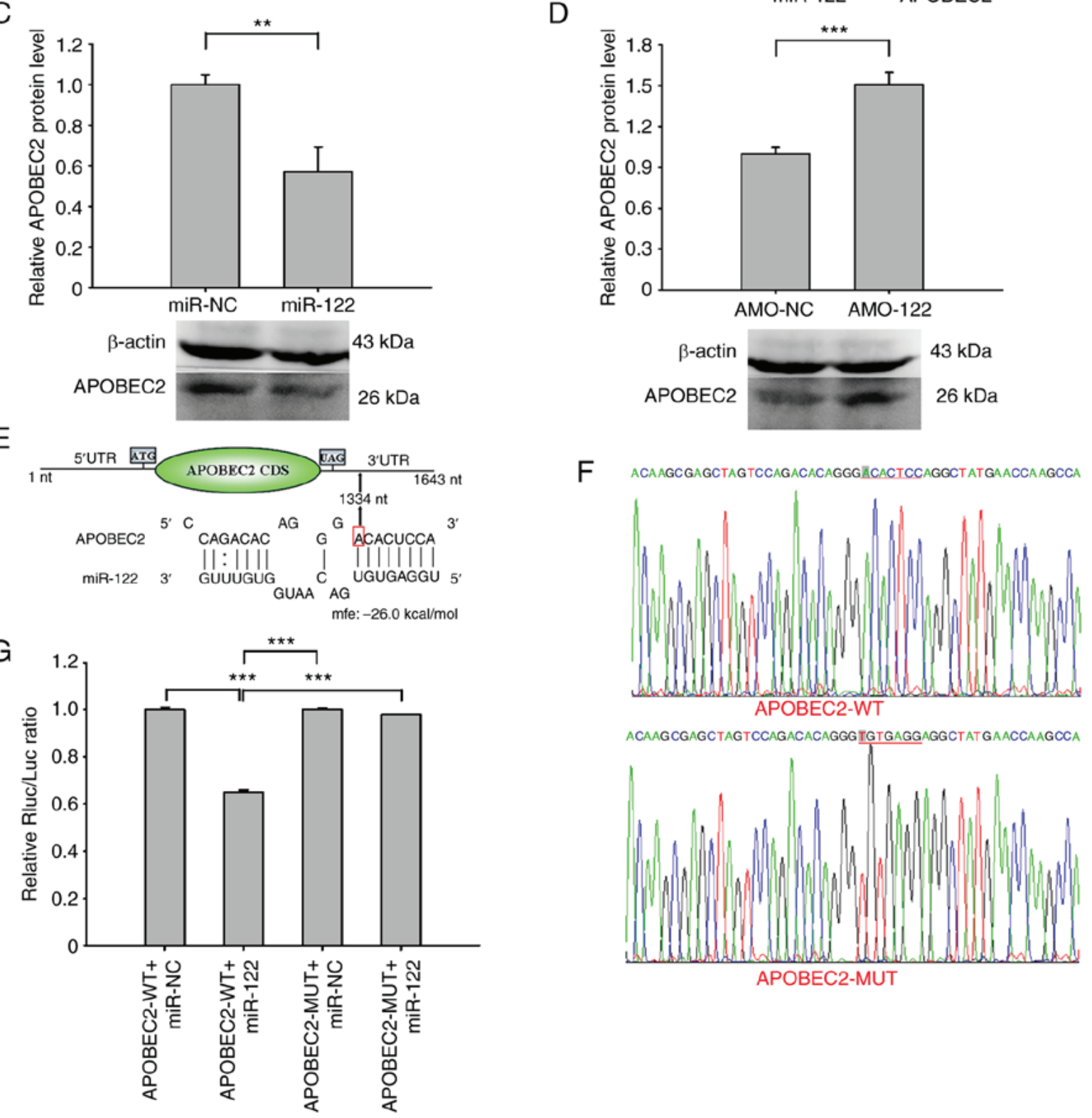

Figure 5. Validation of miR-122 targeting APOBEC2 mRNA. The expression levels of miR-122 and APOBEC2 in Huh7 cells transfected with miR-NC, miR-122, AMO-NC or AMO-122 were determined. Analysis of (A and B) miR-122 and APOBEC2 mRNA, and (C and D) APOBEC2 protein expression 24 and $48 \mathrm{~h}$ post-transfection by reverse transcription-quantitative PCR and western blotting, respectively. $\beta$-actin served as an internal control. (E) Schematic diagram of potential binding sites for miR-122 in the 3'UTR of APOBEC2 mRNA. The locations of putative miR-122 binding sites in the 3'UTR of APOBEC2 mRNA are marked by arrows at 1,334 nt. (F) WT and MUT nucleotides in the putative target sequence for miR-122 in the APOBEC2 mRNA. The MUT region indicated by the red line was generated by over-lapping PCR to minimize complementarity between miR-122 and the 3'UTR of APOBEC2 mRNA. (G) Relative luciferase activity of Huh7 cells transfected with miR-122 mimics + APOBEC2-WT or APOBEC2-MUT. Huh7 cells were co-transfected with miR-122 mimics or miR-NC and a luciferase reporter plasmid harboring WT or MUT miR binding sites. The effects of miR-122 on luciferase activity were determined by luciferase reporter assays. The activity of Renilla luciferase was normalized to that of firefly luciferase. Data are presented as the mean \pm standard error of the mean $(n=3) .{ }^{*} \mathrm{P}<0.05,{ }^{* *} \mathrm{P}<0.01,{ }^{* * *} \mathrm{P}<0.001$. APOBEC2, apolipoprotein B mRNA-editing enzyme catalytic subunit 2 ; AMO, anti-miR oligonucleotide; mfe, minimum free energy; miR, microRNA; MUT, mutated; NC, negative control; nt, nucleotide, the number counts from the first nucleotide at the 5 ' end of APOBEC2 mRNA; UTR, untranslated region; WT, wild type. 

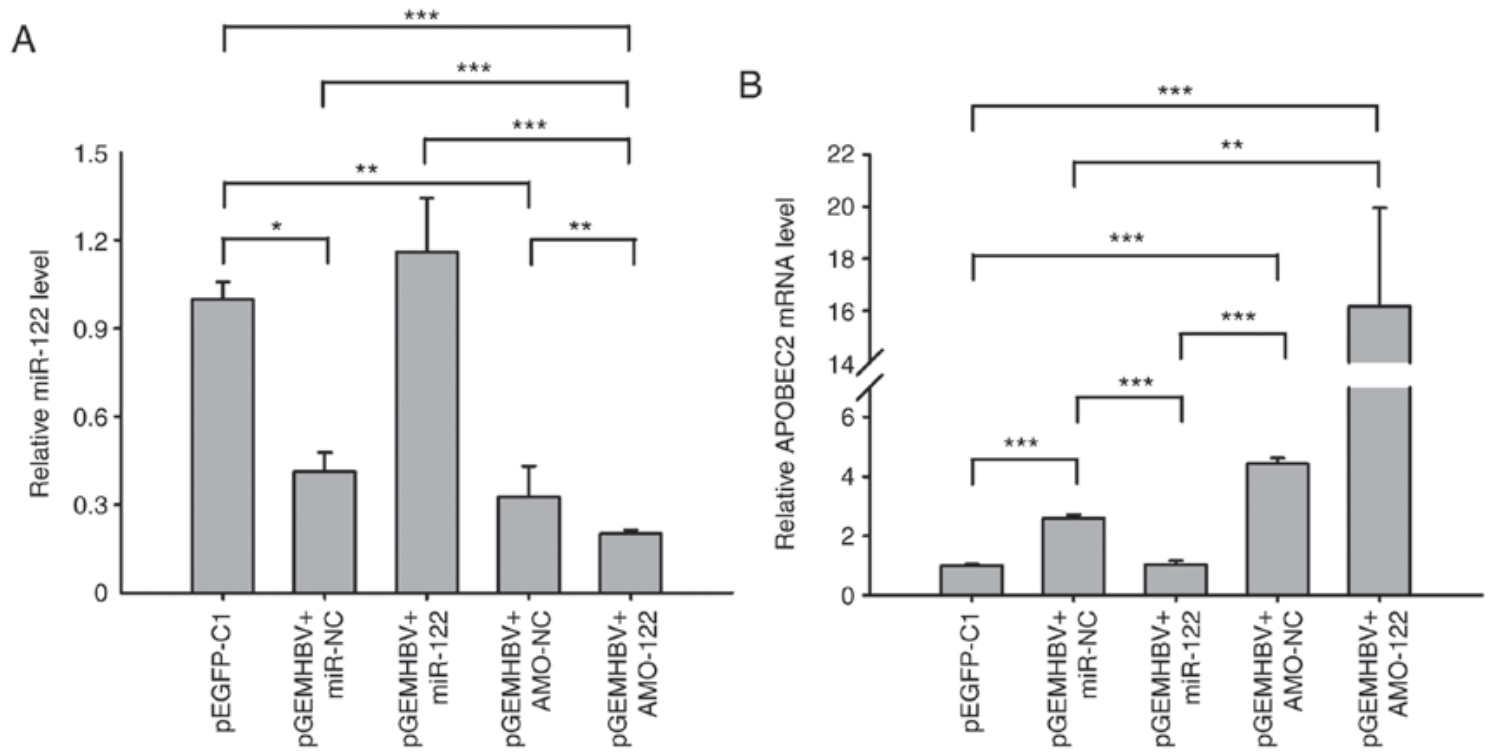

Figure 6. HBV and miR-122 regulate APOBEC2 expression. Huh7 cells were respectively transfected with miR-122, AMO-122 or the corresponding NCs + pGEMHBV. Total RNA was extracted after transfection for $24 \mathrm{~h}$, and the expression of (A) miR-122 and (B) APOBEC2 was determined via reverse transcription-quantitative PCR analysis. Data are presented as the mean \pm standard error of the mean $(\mathrm{n}=3)$. ${ }^{*} \mathrm{P}<0.05,{ }^{* *} \mathrm{P}<0.01,{ }^{* * *} \mathrm{P}<0.001$. APOBEC2, apolipoprotein B mRNA-editing enzyme catalytic subunit 2; AMO, anti-miR oligonucleotide; EGFP, enhanced green fluorescent protein; HBV, hepatitis B virus; miR, microRNA; NC, negative control.

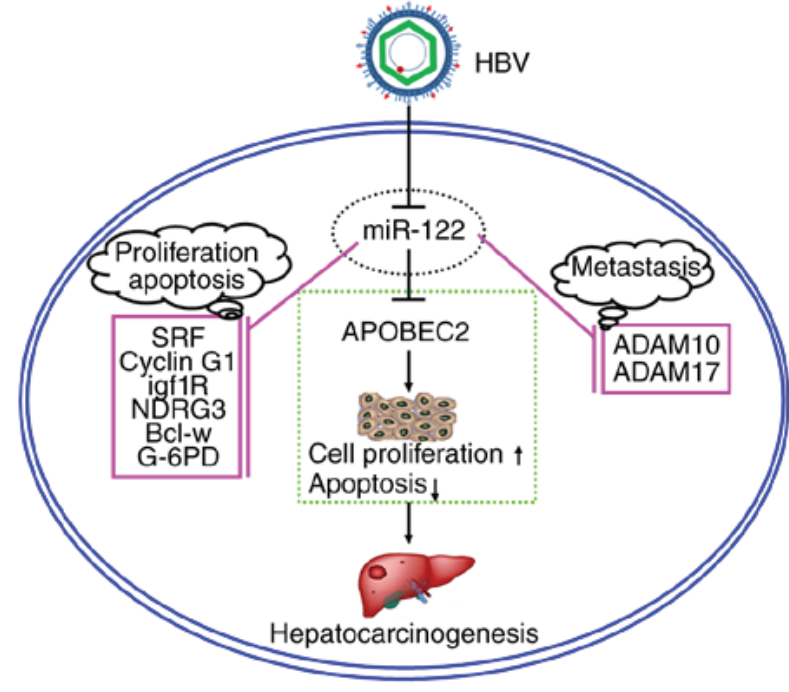

Figure 7. Network of the HBV-miR-122-APOBEC2 signaling cascade and its involvement in liver cancer. The genes in the side boxes are miR-122 targets that have been reported to be directly involved in cell proliferation, the suppression of cell apoptosis and/or the metastasis of liver cancer. APOBEC2, apolipoprotein B mRNA-editing enzyme catalytic subunit 2; HBV, hepatitis B virus; miR, microRNA; SRF, serum response factor; igf1R, insulin-like growth factor 1 receptor; NDRG3, N-myc downstream-regulated gene 3; G-6PD, glucose-6-phosphate-dehydrogenase; ADAM, a disintegrin and metalloprotease family.

of IKK $\varepsilon$ and TNF- $\alpha$ was decreased following the expression of HBV genes. As a multifunctional and pleiotropic inflammatory cytokine, the expression of IL-6 is upregulated in response to viral infection and the presence of certain tumors $(55,56)$. It has been reported that the serum levels of IL-6 are increased in HBV-infected patients; this increase was proposed to serve a crucial role in the induction of immune tolerance against $\mathrm{HBV}$, and could be applied to determine the outcomes of HBV infections (57). Members of the NF- $\mathrm{B}$ family serve crucial roles in various biological process, including inflammation, immune responses, carcinogenesis and apoptosis. It was previously reported that HBV could disrupt the interaction between IKK $\varepsilon$ and DEAD-box RNA helicase, subsequently inhibiting the induction of interferon- $\beta$, which suggests a novel strategy of immune evasion in HBV infections (58). A previous study demonstrated that TNF can inhibit HBV replication and stimulate HBV-specific T-cell responses, which are involved in clearing HBV from infected hepatocytes (59). Chronic inflammation of the liver has been proposed to contribute to the development of liver cancer (60); activation of NF- $\mathrm{KB}$ promoted APOBEC2 expression in hepatocytes (30). Similar to the effects of HBV gene expression, including the significant upregulation of APOBEC2, overexpression of APOBEC2 induced similar effects on the aforementioned inflammatory factors. This suggested that APOBEC2 may act as a factor linking inflammation and the oncogenicity of $\mathrm{HBV}$; however, further investigation is required.

In conclusion, the findings of the present study may provide novel insight the molecular mechanisms underlying HBV-associated carcinogenesis, comprising downregulation of miR-122, which targets APOBEC2, inducing its expression to promote the growth of liver cancer cells. Due to the interactions between miRNAs and their targets in host cells, these findings may serve as a basis for future investigations into the development of liver cancer under conditions of HBV infection, potentially improving understanding regarding how HBV modulates host cell signaling pathways via a variety of mechanisms.

\section{Acknowledgements}

The authors would like to thank Professor Zhaohua Zhong (Harbin Medical University) for technical assistance. 
A

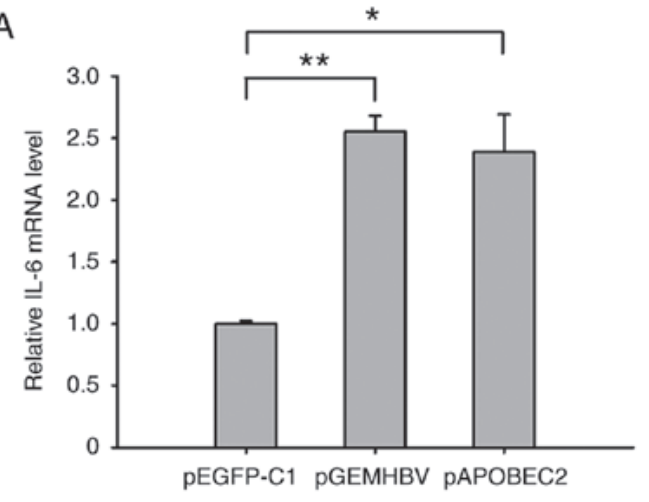

B

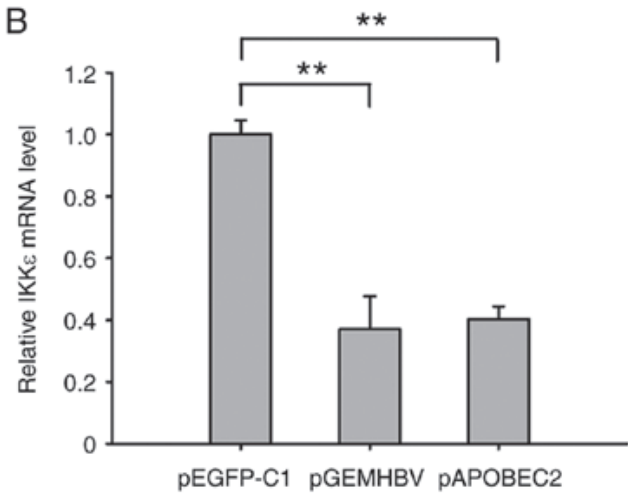

C

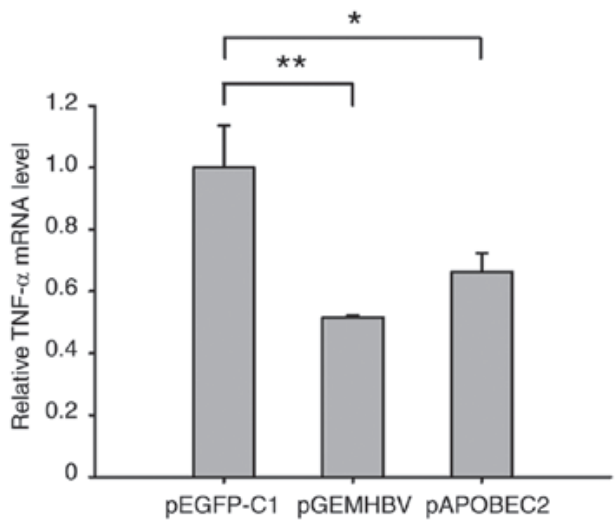

Figure 8. HBV and APOBEC2 modulate the expression of IL-6, IKK $\varepsilon$ and TNF- $\alpha$. Huh7 cells at $70 \%$ confluence were transfected with pGEMHBV or pAPOBEC2 for $24 \mathrm{~h}$. mRNA expression of (A) IL-6, (B) IKKe and (C) TNF- $\alpha$ in Huh7 cells treated with pGEMHBV or pAPOBEC2, as determined by reverse transcription-quantitative polymerase chain reaction. pEGFP-C1 served as a negative control for pGEMHBV and pAPOBEC2. Data are presented as the mean \pm standard error of the mean $(n=3) .{ }^{*} \mathrm{P}<0.05,{ }^{* *} \mathrm{P}<0.01$ and ${ }^{* * * *} \mathrm{P}<0.001$. APOBEC2, apolipoprotein B mRNA-editing enzyme catalytic subunit 2 ; EGFP, enhanced green fluorescent protein; HBV, hepatitis B virus; IKK, IкB kinase; IL-6, interleukin-6; TNF- $\alpha$, tumor necrosis factor- $\alpha$.

\section{Funding}

This work was supported by grants from the National Natural Science Foundation of China (grant nos. 81402267, $81501737,81202296,81601428,81773267$ and 81301703), General Financial Grant from the China Postdoctoral Science Foundation (grant nos. 2014M551271 and 2014M561372), Heilongjiang Postdoctoral Fund (grant no. LBH-Z14164), The Fundamental Research Funds for the Provincial Universities (grant no. 2017JCZX27), The Young Innovative Talent Training Program for Heilongjiang Province Undergraduate Colleges and Universities (grant no. UNPYSCT-2018052), and the Harbin Special Fund for the Scientific and Technological Innovation Scholars (grant no. RC2016QN004073).

\section{Availability of data and materials}

All data generated or analyzed during this study are included in this published article.

\section{Author's contributions}

$\mathrm{AL}, \mathrm{ZZ}$ and $\mathrm{FZ}$ were involved in the conception of the study. $\mathrm{AL}, \mathrm{JW}, \mathrm{XW}$ and $\mathrm{WK}$ performed the experiments. AL, AZ and JQ analyzed the data. AL drafted the primary manuscript. $\mathrm{AL}, \mathrm{AZ}, \mathrm{QZ}, \mathrm{MAQ}, \mathrm{YF}, \mathrm{YL}, \mathrm{WS}, \mathrm{FZ}$ and $\mathrm{ZZ}$ analyzed and interpreted data, produced the figures, further edited the manuscript and revised it critically. FZ and ZZ supervised the whole study and approved the final version of the manuscript to be published. All authors reviewed the results and approved the final version of the manuscript.

\section{Ethics approval and consent to participate}

Not applicable.

\section{Patient consent for publication}

Not applicable.

\section{Competing interests}

The authors declare that they have no competing interests.

\section{References}

1. Ferlay J, Soerjomataram I, Ervik M, Dikshit R, Eser S, Mathers C, Rebelo M, Parkin DM, Forman D and Bray F (eds): GLOBOCAN 2012: Estimated Cancer Incidence, Mortality and Prevalence Worldwide in 2012 v1.0. IARC CancerBase No. 11. IARC, Lyon, 2012. https://publications.iarc.fr/Databases/Iarc-Cancerbases/ GLOBOCAN-2012-Estimated-Cancer-Incidence-Mortality-AndPrevalence-Worldwide-In-2012-V1.0-2012.

2. Motola-Kuba D, Zamora-Valdes D, Uribe $M$ and Mendez-Sanchez N: Hepatocellular carcinoma. An overview. Ann Hepatol 5: 16-24, 2006.

3. Fattovich G, Stroffolini T, Zagni I and Donato F: Hepatocellular carcinoma in cirrhosis: Incidence and risk factors. Gastroenterology 127 (5 Suppl 1): S35-S50, 2004. 
4. Venook AP, Papandreou C, Furuse J and de Guevara LL: The incidence and epidemiology of hepatocellular carcinoma: A global and regional perspective. Oncologist 15 (Suppl 4): S5-S13, 2010.

5. Wei Y, Neuveut C, Tiollais P and Buendia MA: Molecular biology of the hepatitis $\mathrm{B}$ virus and role of the $\mathrm{X}$ gene. Pathol Biol (Paris) 58: 267-272, 2010.

6. Luo N, Cai Y, Zhang J, Tang W, Slagle BL, Wu X and He S: The $\mathrm{C}$-terminal region of the hepatitis $\mathrm{B}$ virus $\mathrm{X}$ protein is required for its stimulation of HBV replication in primary mouse hepatocytes. Virus Res 165: 170-178, 2012.

7. Geng X, Huang C, Qin Y, McCombs JE, Yuan Q, Harry BL, Palmer AE, Xia NS and Xue D: Hepatitis B virus X protein targets $\mathrm{Bcl}-2$ proteins to increase intracellular calcium, required for virus replication and cell death induction. Proc Natl Acad Sci USA 109: 18471-18476, 2012

8. Sze KM, Chu GK, Lee JM and Ng IO: C-terminal truncated hepatitis $\mathrm{B}$ virus $\mathrm{x}$ protein is associated with metastasis and enhances invasiveness by C-Jun/matrix metalloproteinase protein 10 activation in hepatocellular carcinoma. Hepatology 57: 131-139, 2013

9. Yip WK, Cheng AS, Zhu R, Lung RW, Tsang DP, Lau SS, Chen Y, Sung JG, Lai PB, Ng EK, et al: Carboxyl-terminal truncated $\mathrm{HBx}$ regulates a distinct microRNA transcription program in hepatocellular carcinoma development. PLoS One 6: e22888, 2011.

10. Xiao CX, Yang XN, Huang QW, Zhang YQ, Lin BY, Liu JJ Liu YP, Jazag A, Guleng B and Ren JL: ECHS1 acts as a novel HBsAg-binding protein enhancing apoptosis through the mitochondrial pathway in HepG2 cells. Cancer Lett 330: 67-73, 2013

11. Liu YP, Yang XN, Jazag A, Pan JS, Hu TH, Liu JJ, Guleng B and Ren JL: HBsAg inhibits the translocation of JTB into mitochondria in HepG2 cells and potentially plays a role in HCC progression. PLoS One 7: e36914, 2012.

12. Pan JS, Zhou F, Xie CX, Cai JY, Chen JM, Zhang ZP, Dong J, $\mathrm{Xu}$ HZ, Shi HX and Ren JL: Aldolase A-HBsAg interaction and its effect on ultraviolet radiation induced apoptosis in 293FT cells. J Gastroenterol Hepatol 25: 1702-1709, 2010.

13. Sung WK, Zheng H, Li S, Chen R, Liu X, Li Y, Lee NP, Lee WH, Ariyaratne PN, Tennakoon C, et al: Genome-wide survey of recurrent $\mathrm{HBV}$ integration in hepatocellular carcinoma. Nat Genet 44: 765-769, 2012.

14. Shafritz DA, Shouval D, Sherman HI, Hadziyannis SJ and Kew MC: Integration of hepatitis B virus DNA into the genome of liver cells in chronic liver disease and hepatocellular carcinoma. Studies in percutaneous liver biopsies and post-mortem tissue specimens. N Engl J Med 305: 1067-1073, 1981

15. Park YM, Jang JW, Yoo SH, Kim SH, Oh IM, Park SJ, Jang YS and Lee SJ: Combinations of eight key mutations in the X/preC region and genomic activity of hepatitis B virus are associated with hepatocellular carcinoma. J Viral Hepat 21: 171-177, 2014.

16. Xu HZ, Liu YP, Guleng B and Ren JL: Hepatitis B virus-related hepatocellular carcinoma: Pathogenic mechanisms and novel therapeutic interventions. Gastrointest Tumors 1: 135-145, 2014.

17. Sell S and Leffert HL: Liver cancer stem cells. J Clin Oncol 26: 2800-2805, 2008

18. Das A and Maini MK: Innate and adaptive immune responses in hepatitis B virus infection. Dig Dis 28: 126-132, 2010

19. Rogozin IB, Basu MK, Jordan IK, Pavlov YI and Koonin EV: APOBEC4, a new member of the AID/APOBEC family of polynucleotide (deoxy)cytidine deaminases predicted by computational analysis. Cell Cycle 4: 1281-1285, 2005

20. Prochnow C, Bransteitter R and Chen XS: APOBEC deaminases-mutases with defensive roles for immunity. Sci China $C$ Life Sci 52: 893-902, 2009.

21. Teng B, Burant CF and Davidson NO: Molecular cloning of an apolipoprotein B messenger RNA editing protein. Science 260: 1816-1819, 1993

22. Navaratnam N, Morrison JR, Bhattacharya S, Patel D, Funahashi T, Giannoni F, Teng BB, Davidson NO and Scott J: The p27 catalytic subunit of the apolipoprotein B mRNA editing enzyme is a cytidine deaminase. J Biol Chem 268: 20709-20712, 1993.

23. Mangeat B, Turelli P, Caron G, Friedli M, Perrin L and Trono D: Broad antiretroviral defence by human APOBEC3G through lethal editing of nascent reverse transcripts. Nature 424: 99-103, 2003.

24. Harris RS, Bishop KN, Sheehy AM, Craig HM Petersen-Mahrt SK, Watt IN, Neuberger MS and Malim MH: DNA deamination mediates innate immunity to retroviral infection. Cell 113: 803-809, 2003.

25. Suspene R, Guetard D, Henry M, Sommer P, Wain-Hobson S and Vartanian JP: Extensive editing of both hepatitis B virus DNA strands by APOBEC3 cytidine deaminases in vitro and in vivo. Proc Natl Acad Sci USA 102: 8321-8326, 2005.
26. Muramatsu M, Sankaranand VS, Anant S, Sugai M, Kinoshita K, Davidson NO and Honjo T: Specific expression of activation-induced cytidine deaminase (AID), a novel member of the RNA-editing deaminase family in germinal center B cells. J Biol Chem 274: 18470-18476, 1999

27. Neuberger MS, Harris RS, Di Noia J and Petersen-Mahrt SK: Immunity through DNA deamination. Trends Biochem Sci 28 : 305-312, 2003.

28. Liao W, Hong SH, Chan BH, Rudolph FB, Clark SC and Chan L: APOBEC-2, a cardiac- and skeletal muscle-specific member of the cytidine deaminase supergene family. Biochem Biophys Res Commun 260: 398-404, 1999.

29. Anant S, Mukhopadhyay D, Sankaranand V, Kennedy S, Henderson JO and Davidson NO: ARCD-1, an apobec-1-related cytidine deaminase, exerts a dominant negative effect on $\mathrm{C}$ to U RNA editing. Am J Physiol Cell Physiol 281: C1904-C1916, 2001.

30. Matsumoto T, Marusawa H, Endo Y, Ueda Y, Matsumoto Y and Chiba T: Expression of APOBEC2 is transcriptionally regulated by NF-kappaB in human hepatocytes. FEBS Lett 580: 731-735, 2006.

31. Okuyama S, Marusawa H, Matsumoto T, Ueda Y, Matsumoto Y, Endo Y, Takai A and Chiba T: Excessive activity of apolipoprotein B mRNA editing enzyme catalytic polypeptide 2 (APOBEC2) contributes to liver and lung tumorigenesis. Int J Cancer 130: 1294-1301, 2012.

32. Bandopadhyay M, Sarkar N, Datta S, Das D, Pal A, Panigrahi R, Banerjee A, Panda CK, Das C, Chakrabarti S and Chakravarty R: Hepatitis B virus X protein mediated suppression of miRNA-122 expression enhances hepatoblastoma cell proliferation through cyclin G1-p53 axis. Infect Agent Cancer 11: 40, 2016.

33. Scaglioni PP, Melegari M and Wands JR: Posttranscriptional regulation of hepatitis $\mathrm{B}$ virus replication by the precore protein. J Virol 71: 345-353, 1997

34. Livak KJ and Schmittgen TD: Analysis of relative gene expression data using real-time quantitative PCR and the 2(-Delta Delta C(T)) method. Methods 25: 402-408, 2001.

35. Vallee A, Lecarpentier Y and Vallee JN: Targeting the canonical WNT/ $\beta$-catenin pathway in cancer treatment using non-steroidal anti-inflammatory drugs. Cells 8: E726, 2019.

36. Kumari N, Dwarakanath BS, Das A and Bhatt AN: Role of interleukin-6 in cancer progression and therapeutic resistance. Tumour Biol 37: 11553-11572, 2016.

37. Göktuna SI, Diamanti MA and Chau TL: IKKs and tumor cell plasticity. FEBS J 285: 2161-2181, 2018.

38. Zubair H, Azim S, Srivastava SK, Ahmad A, Bhardwaj A, Khan MA, Patel GK, Arora S, Carter JE, Singh S and Singh AP: Glucose metabolism reprogrammed by overexpression of IKKepsilon promotes pancreatic tumor growth. Cancer Res 76: 7254-7264, 2016

39. Balkwill F: TNF-alpha in promotion and progression of cancer. Cancer Metastasis Rev 25: 409-416, 2006.

40. Li C, Wang Y, Wang S, Wu B, Hao J, Fan H, Ju Y, Ding Y, Chen L, Chu X, et al: Hepatitis B virus mRNA-mediated miR-122 inhibition upregulates PTTG1-binding protein, which promotes hepatocellular carcinoma tumor growth and cell invasion. J Virol 87: 2193-2205, 2013.

41. Cascalho M: Advantages and disadvantages of cytidine deamination. J Immunol 172: 6513-6518, 2004.

42. Chen SH, Habib G, Yang CY, Gu ZW, Lee BR, Weng SA, Silberman SR, Cai SJ, Deslypere JP and Rosseneu M: Apolipoprotein B-48 is the product of a messenger RNA with an organ-specific in-frame stop codon. Science 238: 363-366, 1987.

43. Yamanaka S, Balestra ME, Ferrell LD, Fan J, Arnold KS, Taylor S, Taylor JM and Innerarity TL: Apolipoprotein B mRNA-editing protein induces hepatocellular carcinoma and dysplasia in transgenic animals. Proc Natl Acad Sci USA 92: 8483-8487, 1995.

44. Okazaki IM, Hiai H, Kakazu N, Yamada S, Muramatsu M, Kinoshita $\mathrm{K}$ and Honjo T: Constitutive expression of AID leads to tumorigenesis. J Exp Med 197: 1173-1181, 2003.

45. Morisawa T, Marusawa H, Ueda Y, Iwai A, Okazaki IM, Honjo T and Chiba T: Organ-specific profiles of genetic changes in cancers caused by activation-induced cytidine deaminase expression. Int J Cancer 123: 2735-2740, 2008.

46. Girard M, Jacquemin E, Munnich A, Lyonnet S and Henrion-Caude A: miR-122, a paradigm for the role of microRNAs in the liver. J Hepatol 48: 648-656, 2008.

47. Lewis AP and Jopling CL: Regulation and biological function of the liver-specific miR-122. Biochem Soc Trans 38: 1553-1557, 2010. 
48. Gramantieri L, Ferracin M, Fornari F, Veronese A, Sabbioni S, Liu CG, Calin GA, Giovannini C, Ferrazzi E, Grazi GL, et al: Cyclin G1 is a target of miR-122a, a microRNA frequently down-regulated in human hepatocellular carcinoma. Cancer Res 67: 6092-6099, 2007.

49. Fan CG, Wang CM, Tian C, Wang Y, Li L, Sun WS, Li RF and Liu YG: miR-122 inhibits viral replication and cell proliferation in hepatitis B virus-related hepatocellular carcinoma and targets NDRG3. Oncol Rep 26: 1281-1286, 2011.

50. Lin CJ, Gong HY, Tseng HC, Wang WL and Wu JL: miR-122 targets an anti-apoptotic gene, Bcl-w, in human hepatocellular carcinoma cell lines. Biochem Biophys Res Commun 375: 315-320, 2008

51. Barajas JM, Reyes R, Guerrero MJ, Jacob ST, Motiwala T and Ghoshal K: The role of miR-122 in the dysregulation of glucose-6-phosphate dehydrogenase (G6PD) expression in hepatocellular cancer. Sci Rep 8: 9105, 2018.

52. Bai S, Nasser MW, Wang B, Hsu SH, Datta J, Kutay H, Yadav A, Nuovo G, Kumar P and Ghoshal K: MicroRNA-122 inhibits tumorigenic properties of hepatocellular carcinoma cells and sensitizes these cells to sorafenib. J Biol Chem 284: 32015-32027, 2009.

53. Tsai WC, Hsu PW, Lai TC, Chau GY, Lin CW, Chen CM, Lin CD, Liao YL, Wang JL, Chau YP, et al: MicroRNA-122, a tumor suppressor microRNA that regulates intrahepatic metastasis of hepatocellular carcinoma. Hepatology 49: 1571-1582, 2009.
54. Waidmann O, Bihrer V, Pleli T, Farnik H, Berger A, Zeuzem S, Kronenberger B and Piiper A: Serum microRNA-122 levels in different groups of patients with chronic hepatitis B virus infection. J Viral Hepat 19: e58-e65, 2012.

55. Song le H, Binh VQ, Duy DN, Kun JF, Bock TC, Kremsner PG and Luty AJ: Serum cytokine profiles associated with clinical presentation in vietnamese infected with hepatitis B virus. J Clin Virol 28: 93-103, 2003.

56. Porta C, De Amici M, Quaglini S, Paglino C, Tagliani F, Boncimino A, Moratti R and Corazza GR: Circulating interleukin-6 as a tumor marker for hepatocellular carcinoma. Ann Oncol 19: 353-358, 2008.

57. Lan T, Chang L, Wu L and Yuan YF: IL-6 plays a crucial role in HBV infection. J Clin Transl Hepatol 3: 271-276, 2015.

58. Wang $\mathrm{H}$ and Ryu WS: Hepatitis B virus polymerase blocks pattern recognition receptor signaling via interaction with DDX3: Implications for immune evasion. PLoS Pathog 6: e1000986, 2010.

59. Marinos G, Naoumov NV, Rossol S, Torre F, Wong PY, Gallati H, Portmann B and Williams R: Tumor necrosis factor receptors in patients with chronic hepatitis B virus infection. Gastroenterology 108: 1453-1463, 1995.

60. Thorgeirsson SS and Grisham JW: Molecular pathogenesis of human hepatocellular carcinoma. Nat Genet 31: 339-346, 2002. 